\title{
NON-DESTRUCTIVE MONITORING AND TECHNICAL EVALUATION CONDITIONS OF THE MONUMENT ALEXANDER III
}

\author{
Anatolii Potapov¹, Igor Pavlov², lana Verkhovskaia3,4 \\ 1,2 Saint-Petersburg Mining University \\ 21st Line, 21, St. Petersburg, Russia \\ ${ }^{3}$ ITMO University \\ Kronverksky Pr., 49, St. Petersburg, Russia \\ ${ }^{4}$ Saint-Petersburg State University of Industrial Technologies and Design \\ Bolshaya Morskaya St., 18 St. Petersburg, Russia \\ 1 apot@mail.ru, ${ }^{2}$ pavlov33@mail.ru ${ }^{3}$ yana_rus@inbox.ru
}

\begin{abstract}
The article presents the methods of non-destructive testing and evaluation of monuments of cultural heritage, verified by the example of technical analysis of the structure and the defective condition of the monument to Alexander III (St. Petersburg). The methodology includes a set of scientific and technical activities and consists of several blocks of analysis of the composition of materials and design features: visual-optical, capillary, acoustic-ultrasonic, acousticultrasonic pulsed, thermal-imaging, X-ray fluorescence and metallographic.

The main results are the assessment of the technical condition of the monument to Alexander III, contributing to the development of restoration activities and conservation. The practical significance of the work is the accumulation of data about the structure and material of the monument, the development of recommendations for further research and restoration activities of similar objects of historical, cultural, and architectural value.
\end{abstract}

\section{Keywords}

Non-destructive control methods, flaw detection, preservation of cultural heritage, cultural and architectural monuments.

\section{Introduction}

Numerous methods of researching monuments of sculpture and architecture are diverse. They are based on a wide variety of scientific and technical methods and are very interesting and time-consuming, often yielding unexpected results, since almost all monuments do not have technical documentation, were made in a single copy and reflect the level of technical achievements of teams of authors, individual authors and characterize the level of technical achievements and standard technical solutions of the era, which they represent.

By virtue of the above features, the method of monitoring the technical condi-tion of monuments of sculpture and architecture may differ dramatically from the methods of technical control in engineering and instrument-making, but also has much in common in terms of the methods used, ways of their implementation, processing and presentation of results.

\section{Subject, tasks and methods}

This paper presents a research methodology based on non-destructive methods of controlling materials, structure and technical condition of monumental sculptures by the example of the results of a technical survey of the monument to Alexander III.

The purpose of the research was to establish the technical condition and design features, including internal structure and its defective state to search for the solution to the problem of relocating the monument to a new exhibition site, as well as to accumulate factual material about the structure and material of the monument and make recommendations for further restoration measures (Nagaeva et al., 2018). It is worth noting that during the primary visual inspection of the monument to Alexander III, it was stated that during previous relocations significant defects in the material of the base, namely the formation of a large crack in the plinth, about a meter long, were found that could have unpredictable consequences for the integrity of the monument itself during its transportation and further storage. Preliminary investigations showed that the monument (herein-after the "monument" means its bronze cast part without a pedestal and lost parts: horse reins, which were in Alexander III's hand, etc.) (State Duma, 2019) consists of five parts: the rider with 
the saddle, the front part of the horse, the back part of the horse, the horse's head and the plinth.

The monument is a relatively young work of cast monumental sculpture of St. Petersburg. P. Trubetskoy in his design took into account the experience of operating bronze sculptures in a humid sulfur atmosphere of the city with sharp temperature changes.

There is no steel frame in the structure of the monument, (which is present in monuments of similar mass to Peter I and Nicholas I), and therefore, the monument does not have significant defects such as long developed cracks caused by electrocorrosion between the bronze of the monument and the iron of the frame and the subsequent penetration of moisture into the emptiness of the sculpture breaking the material during freezing - defects typical of the monument to Peter I by Rastrelli.

The sculptor calculated the structural strength of the monument, but only in relation to the natural conditions of operation: many years under the influence of atmospheric phenomena (wind, snow, acid and alkaline rains of the industrial city, temperature drops), but only at rest, on a monolithic granite pedestal. The relocation of the monument was supposed only once for its installation on the pedestal in the middle of Znamenskaya Square. At the same time, the archival search did not allow to unequivocally establish whether the monument was delivered to Znamenskaya Square in assembled form or was mounted on site.

The sculptor did not assume that the assembled monument would be relocated many times, be used during the shooting of the film in the form of scenery, spend several years lying on its side in the Mikhailovsky Garden, would be subjected to a direct hit of a highexplosive bomb, be filled up with sand during the war and even in the Russian Museum would stand in the backyard for several decades without a foundation.

All of the above types of loads relate to extreme ones, and therefore, when the question of the next relocation of the monument to a new exhibition site was raised, a serious examination of the monument as a composite engineering structure with a complex, little-known previous load history was required.

First of all, it was necessary to determine the rigidity and strength of the whole structure, for which it was required to determine the structure of the monument, the material, its composition, the defective condition and based on the data obtained to predict the behavior of the structure during slinging, lifting, moving by road and to suggest a method of relocation that excludes destruction of the structure and its irreversible deformations (Rebrikova, 2008; Baranov, 2013).

The destructive method of research in this case is not applicable: any cutting and sampling, etc., is impossible, since the object of study is unique. It is possible to determine its chemical composition only on the basis of $X$-ray diffraction analysis of the metal scraping.

Therefore, in the present case, the main emphasis was on the use of non-destructive testing methods: flaw detection and diagnostics (Gavrilenko et al., 2008). The complexity of the scientific formulation of the problem, in this case, was also in the fact that almost all methods of non-destructive testing are calibrated. In our case, due to the uniqueness of the control object, it was necessary to develop non-destructive testing techniques excluding additional calibration.

The complex, widespread use of flaw detection methods was also due to the fact that after identifying all defects and their boundaries, the metal of the monument may have significant variability in the properties of stiffness and strength at various casting sites.

The mechanical properties of the material of the monument depend on the quantitative ratio of the components in bronze, which may be different in various places of the same casting, and even more so in different castings, intercrystalline corrosion, fine porosity of individual casting sites (as, for example, on the back of the left rear horse's leg, etc.). Not only the strength and deformability properties of bronze depend on these parameters, but also all the other physical characteristics: acoustic, electrical, thermotechnical, etc.

Knowing the values of some of these characteristics, it is possible without destroying the material of the monument to predict the magnitude of mechanical characteristics of bronze in the places of local loading of the monument that the researcher is interested in. To solve these issues in the course of the work, non-destructive diagnostic methods were used (Chistyakov, Krogius, 2014; Firsova, 2012).

In the course of the work, the optimal schemes for slinging, lifting and relocating of the monument were determined based on the results of the non-destructive testing.

\section{Brief historical background}

The monument to Emperor Alexander III (Figure 1) was built during 1900-1909 according to the project of P. Trubetskoy. The casting of the monument was carried

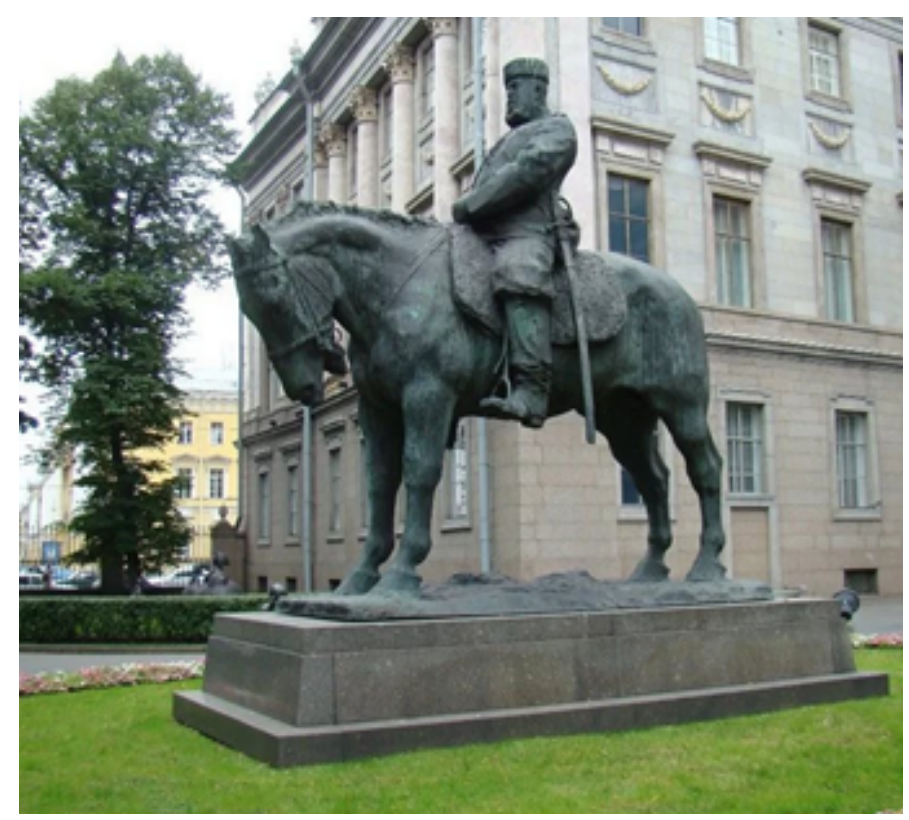

Figure 1. The monument to Emperor Alexander III according to P. Trubetskoy's project. 
out in two places: the figure of the rider was cast in the workshops of the Academy of Arts, the rest of the details - at the Obukhov Factory [8].

The opening of the monument to Emperor Alexander III took place on May 23, 1909. The monument was erected

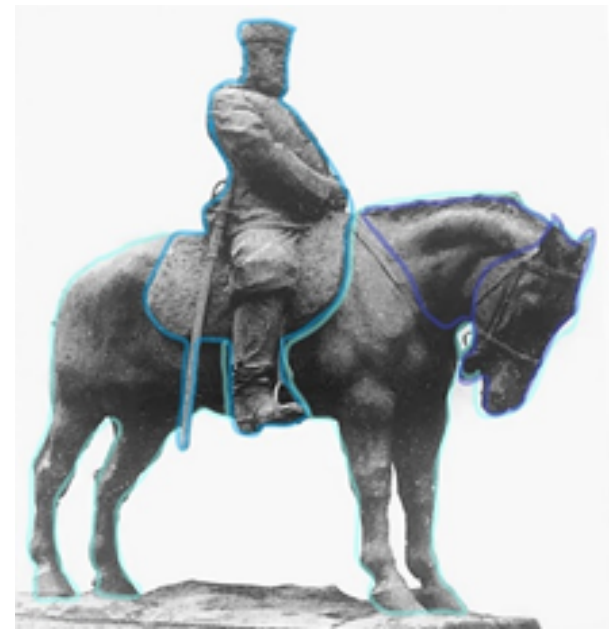

Figure 2. The scheme of elements of the monument to Emperor Alexander III.

on Znamenskaya Square.

The development and manufacture of the monument cost 1,500,000 rubles. "The emperor is depicted sitting astride a horse, in full-dress uniform of a general, the left hand holds the reins of the horse with power, but calmly, and the right one smartly rests on the side. On the front side of the pedestal facing the Nikolaevsky railway station, the inscription was made: To Emperor Alex-ander III, the sovereign founder of the Great Siberian Way" (Pedashenko, 1912). The casting of the equestrian statue was entrusted to Florentine master Robecchi (Schmidt, 1989).

The monument has caused a lot of lively and passionate disputes and almost all recognized it as unsuccessful. For example, academician A.N. Benois wrote: "One can only regret that Trubetskoy because of the lack of knowledge and technical skills in the statue he created, finally disappointed many of those who hoped for him".

It was thanks to the striking portrait resemblance of the monument to the Emperor, despite numerous negative reviews about the monument itself, that the royal family agreed to the opening of the monument (Rogachevsky, 1965).

In the first years of Soviet power, bronze letters were removed from the pedestal and the inscription with the content corresponding the time ("Scare-crow") was made.

In 1937 the "gates of the city" were recognized as an unsuitable place for such a monument, which was an "evil, murderous satire on autocracy", and the monument was removed from Znamenskaya Square to the courtyard of the Russian Museum, where it was located at the time of the research (Rogachevsky, 1965).

During the war, the monument was transported to the Mikhailovsky Garden, laid on its side and covered with sand. On October 17, 1941, the monument was hit by a high-explosive bomb. Thanks to the sandy backfill, the monument did not receive any visible damage.

After the war, the monument was again returned to the courtyard of the Russian Museum.

To date, the monument is different from the prerevolutionary state due to the following losses:

1. overhead letters of the inscription removed at the change of the inscrip-tion in the 1920s;

2. a monolithic pedestal of pink granite blocks as it was dismounted during the dismantling of the monument, sawn into pieces and used, in particular, for the pedestal of the monument to Rimsky-Korsakov.

3. separately manufactured overhead reins of a horse, which were in the rider's left hand.

\section{Results and discussion \\ Control of the material and structure of the monument}

To clarify the possibility of applying loads to the monument, the occur-rence of which is possible during slinging and transportation, taking into account the identified defects in the material of the monument, its physical and mechanical characteristics, thickness in dangerous sections and bearing capacity of connections of individual elements, a complex of nondestructive testing methods was proposed (Potapov, 1980).. The complex includes the following methods:

1.visual-optical - to detect external defects, i.e. defects that reach the surface (internal or external) of the metal of the monument, as well as to determine the internal structure of the monument, the connection of its individual parts and their technical condition;

2. capillary - to determine the presence of microcracks in strained places, their actual size and orientation;

3. acoustic-ultrasonic - to determine the presence of internal defects, their boundaries and coordinates, i.e. for flaw detection;

4. acoustic-ultrasonic - to determine the thickness of the metal in the most strained places, i.e. for thickness gauging;

5. acoustic-ultrasonic pulse - to determine the physical and mechanical properties of the metal in the places of the greatest loads during lifting and relocating of the monument, i.e. for diagnostics;

6. thermal-imaging - to determine the solidity of the connections of indi-vidual parts of the monument;

7. X-ray fluorescent - to determine the chemical composition of the mate-rial;

8. metallographic - to identify the microstructure of the material.

Studies and analysis of the experience available in our country (the study of monuments to Peter I and Nicholas I in St. Petersburg) and abroad (the study of the figure crowning the Capitol in Washington) showed that the choice was made correctly.

When conducting research on the monument to Peter I, gamma flaw detec-tion was also used to determine the presence and orientation of metal fittings embedded in bronze (in particular, in the legs of the horse). In our 

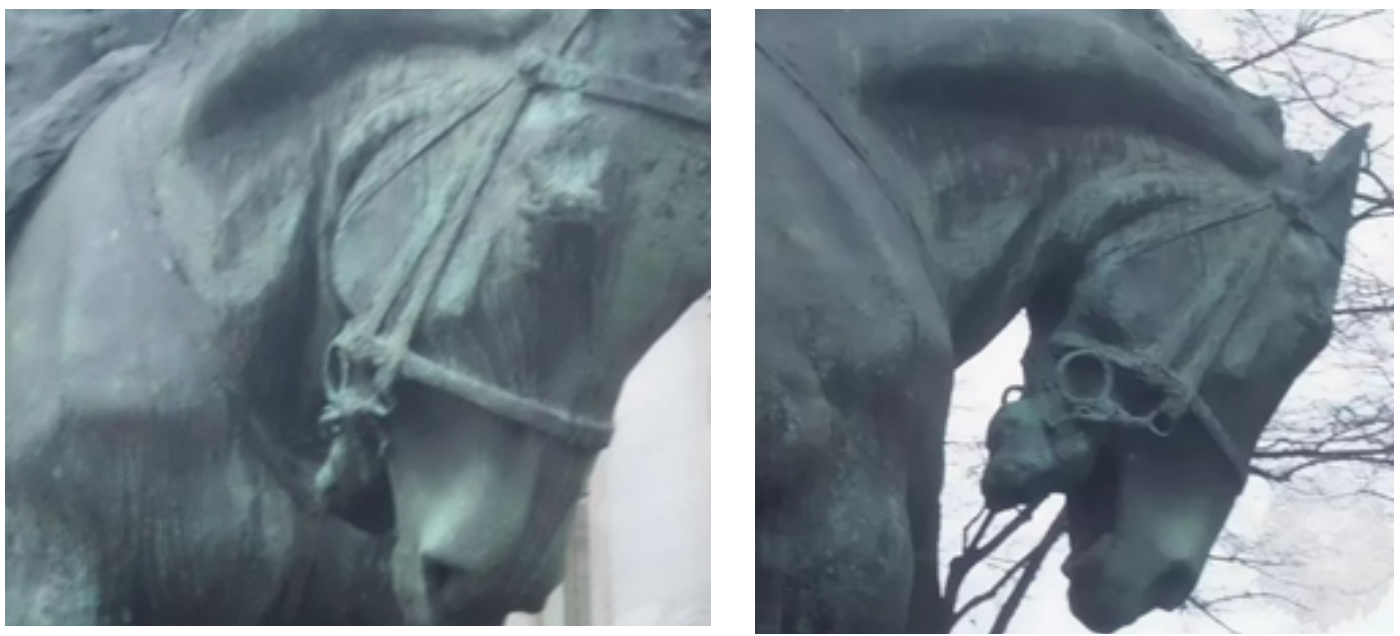

Figure 3. The scheme of elements of the monument to Emperor Alexander III - the head of the horse.

case, such a task was not set, and all other issues were solved using the methods proposed above. In addition, it is necessary to take into account that in order to conduct gamma flaw detection, special security measures are required and specialized services should be involved. Therefore, carrying out flaw detection by this method was impossible in the conditions of close proximity of premises with a large number of people.

The study of the structure of the monument, the connections of its parts and individual defects

No documents on the structure of the monument have been preserved. Therefore, it was not even clear whether the monument has a steel frame inside a hollow structure (as in the monument to Nicholas I or a steel frame in separate bearing elements, as in the monument to Peter I).

With the help of a special technical flexible controlled endoscope, the in-ternal structure of the monument and the state of fasteners were examined. It was found out that the monument consists of four parts: the head of the horse, the front part of the horse, the back part of the horse, the figure of Alexander III.

The front and back parts of the horse are connected with two mechanical-ly machined half-flanges with the help of bolts with nuts (presumably M14).

The inner line of the conjugation of the horse with the figure of Alexander III has a complex contour. The figure is bolted (presumably with M12 bolts) with nuts. The same figure shows the sketch of the connection of the horse with the figure.

The horse's head is connected to the horse's body with bolts (15 pieces), the heads of which were cut off after mounting. The upper part of the coupling has a gap of 2 $\mathrm{mm}$. In the lower part of the interface, corrosion products and traces of unidentified seal material are visible.

The horse's hooves are inserted into the grooves of the plinth. Through the lower part of the body, holes were drilled and pins were inserted (supposedly $12 \mathrm{~mm}$ in diameter). Besides, the hooves are welded (sealed) around the perimeter. Ultrasonic testing revealed significant heterogeneity and non-penetration.
With the help of a thermal imager, significant gaps (up to $35 \%$ ) were identified along the line of conjugation of the horse's head (weight more than 1.5 tons, length 1.7 meters).

The monument is patinated, has a fairly well-preserved exterior surface, virtually no corrosion damage. Only in some places there are small foci of metal oxidation: the greening of different shades.

Through holes. There are several holes in the monument: technological, from bullets and fragments and casting defects.

Technological holes with a diameter of $25 \mathrm{~mm}$ are located on the plinth and in the lower part of the horse's belly. The metal around the hole is solid.

The monument has several casting defects.

There is a hole of irregular shape measuring $50 \times 60$ $\mathrm{mm}$, partially filled with zinc in the horse's head between the ears. Bronze around the hole is thinned to $5-10 \mathrm{~mm}$.

There is a hole with a diameter of $6 \mathrm{~mm}$ on the rider's boot. There is an oval opening measuring $12 \times 7 \mathrm{~mm}$ in the right thigh of the horseman. There is a hole of $25 \times 15$ $\mathrm{mm}$ on the outside of the boot, the hole in the top of the fist of $80 \times 20 \mathrm{~mm}$. The metal around the hole is thinned. There is a threaded hole of M10 size in the index finger.

There are cast defects such as scabs caused by penetration of molding mixture pieces into the metal during the hardening process. One scab with a size of $70 \times 40 \mathrm{~mm}$ and a depth of $30 \mathrm{~mm}$ was found in the lower part of the arm.

Cavities. There are small cavities on the surface of the monument. The largest number of them is in the front part of the horse's chest of 5-15 mm long, 5-10 mm deep.

Cracks. There are microscopic cracks in the monument. There is a deep crack in the plinth. It starts at a distance of $215 \mathrm{~mm}$ from the front of the plinth on the left side and goes to the right side at a distance of $230 \mathrm{~mm}$ from the front part. It was welded (or smelted) and calked at a distance of $580 \mathrm{~mm}$ from the right side.

Ultrasonic control showed the absence of confluence between the embedment material and the base metal in some places. 


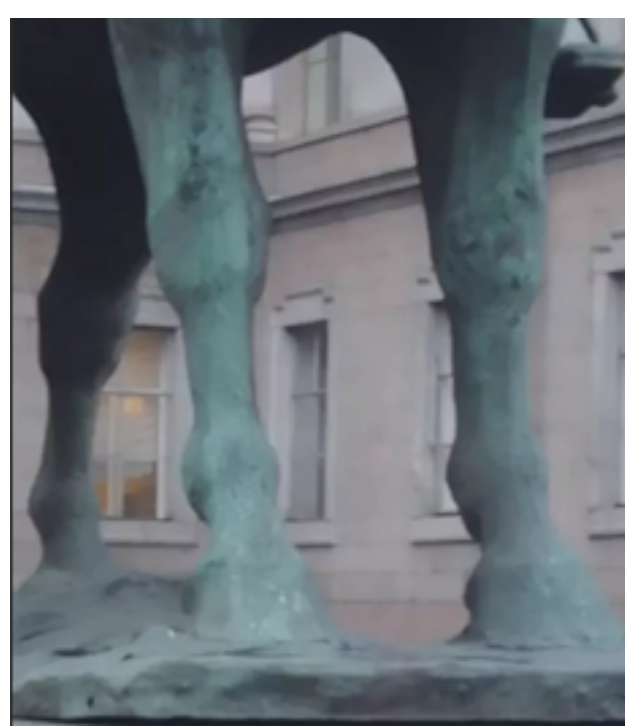

Figure 3. The scheme of elements of the monument to Emperor Alexander III - the front part of the horse.

Seals. The sealing of the hole with a diameter of 85 $\mathrm{mm}$ in the horse's mouth with a zinc-based alloy is in good condition.

A large number of seals is in the rider's figure. Obviously, a fragment of $100 \times 200 \mathrm{~mm}$ is welded in the upper part of the saddle. On the right side of the saddle there is a seal with bronze $130 \times 120 \mathrm{~mm}$ in size. There are seals in the plinth.

The use of the endoscope allowed examining in detail the condition of bolted connections in the horse's belly. The advantage of the endoscope is the presence of an operator-controlled head equipped with a magnifying lens, so the place of control is examined in an enlarged form and even minor defects are detected.

This allowed us to verify the good quality of bolt connections. It should be noted that the advantage of the endoscope is at the same time its disadvantage as the use of a microlens leads to the fact that the field of view and depth of field are very small, so the method is

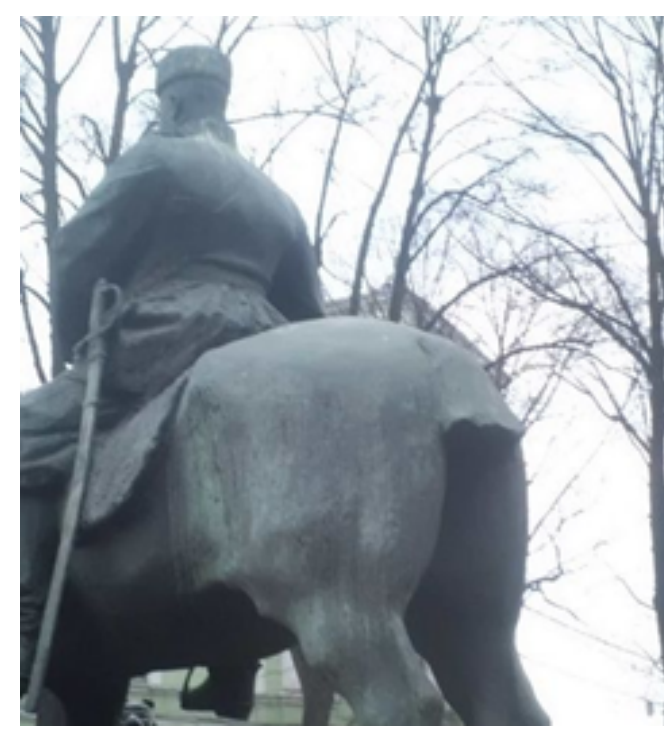

Figure 4. The scheme of elements of the monument to Emperor Alexander III - the back part of the horse. very laborious and tedious for the operator. The method, in such an implementation, can only be recommended for surveying individual sites. Otherwise, television endoscopes should be used.

The survey of the entire internal structure of the monument was carried out visually with the help of a special purpose tubular halogen illuminator and a system of mirrors. There are no special openings for inspecting the monument (as, for example, in the monument to Nicholas I, where there is a special hatch). Therefore, the existing minor openings - through defects - had to be used. Illuminators entered the monument in two ways.

1. A halogen lamp KIM-100 with a power of $100 \mathrm{~W}$ was inserted on a tel-escopic rod through a hole in the lower part of the horse's belly, designed to drain water. Inspection of the internal cavity of the monument was carried out through a similar opening located next to it through the hole in the rider's left boot and through the hole in the upper part of the rider's left hand holding the reins. The inner surface of the monument is very dark, covered with a layer of oxides and dust and therefore strongly absorbs light. Thus, it was possible to establish the absence of internal metal reinforcement and the presence of bolted joints between the elements and their number.

2. For a more detailed examination of the internal structure of the monu-ment, after it had been found to be hollow, it was decided to use a $1300 \mathrm{~W}$ special-purpose halogen lamp KG 220-1300-3, the distinctive feature of which is a rod-like design with the diameter of $8 \mathrm{~mm}$, which allowed to enter it into the monument through the hole in the rider's left fist. Thus, the internal struc-ture of the monument, the method of connecting the individual parts and the presence of defects reaching the internal surface of the monument were studied in detail. However, it was not possible to fully examine the inner surface of the horse's legs. Even the use of special mirrors and lenses did not allow a peek through the existing holes to look inside the horse's legs, into the area of the hock joint, i.e. to the place where a large cluster of porosity was found outside.

Defects of microscopic size, most often - cracks, cannot be detected visually, but they can be stress concentrators and, therefore, are also subject to detection. The greatest accumulation of microcracks by the method of microscopy was found around the rivets (or screw caps) securing the horse's head to the body. Since the horse's head is a console weighing about 1.5 tons, the connec-tion was subjected to the most careful control. The capillary method is most suitable one for the detection of defects of this type.

In our case, due to the poor (from the point of testing) condition of the outer surface of the monument, it was impossible to detect defects as small as micrometers, and there was no need for this, since they could affect the bearing capacity of the monument at loads close to critical, and such loads should not occur in the monument during lifting and transportation. Defects in the form of cracks with an opening of tens of micrometers and more were detected reliably. 

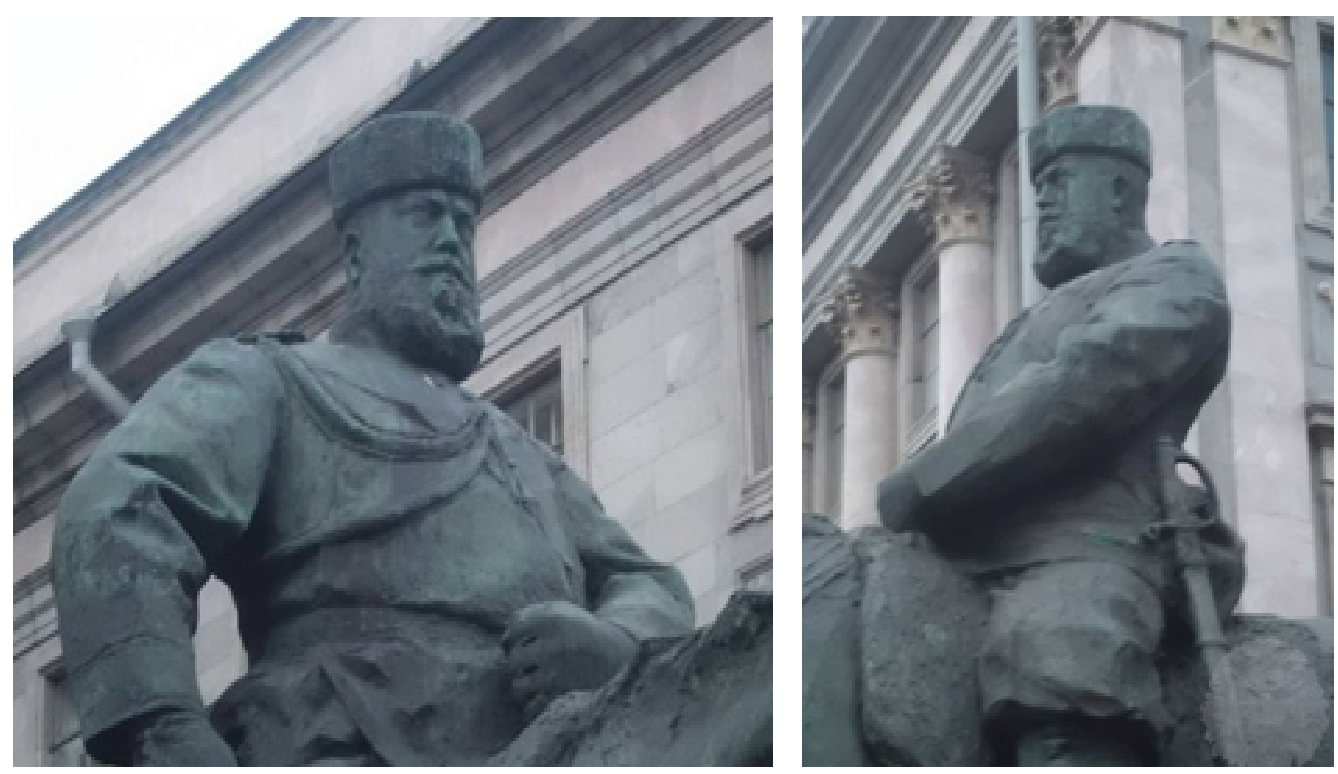

Figure 5. The scheme of elements of the monument to Emperor Alexander III - the figure of Alexander III.

The presence of microscopic cracks around the holes along the martingale was determined, in which there were screw inserts that fasten the horse's head with the body. This was another reason for recommending reinforcement of the horse's head during transportation. Aerosol penetrants of the Italian company Namikon, which allowed detecting very small cracks, were used for the control, but in those places where the surface condition allowed for thorough cleaning. In other places, the capillary method was implemented using the so-called "kerosene sample method", in which kerosene was used as a penetrant, and chalk - as a developing substance. The method has a much lower sensitivity, but works well on a rough, untreated surface, which is almost the entire surface of the monument.

After detection and classification of the defects that reached the surface (internal or external) in the most loaded (during lifting and transportation) places, it was necessary to determine the thickness of the metal and the absence of internal defects: pores, voids, slag and earthen inclusions, etc. For these purposes, the acoustic ultrasonic flaw detection method was used. To effectively apply this method, it is necessary to correctly determine the optimal modes of flaw detection, methods for inputting and receiving ultrasonic vibrations, methods for processing the results, and then choosing a device or several mutually complementary devices that meet these requirements.

The main parameters that determine the test effectiveness in the case under consideration and the principles of their choice (Aleshin, 1989). The correct choice of UT frequency is of great practical importance to obtain the necessary sensitivity during the test. The higher the frequency, the shorter the length of the elastic waves in the controlled product and the better the conditions for their reflec-tion from defects. With an increase in the frequency of sounding, the directivity of radiation and reception increases, due to which the ratio of the energy re-flected from the defect to the total energy introduced into the product, grows. Moreover, it helps to increase the sensitivity of control. However, as the fre-quency rises, the attenuation coefficient of elastic waves in the controlled object increases, the conditions for the passage of waves through the input surface deteriorate, and the intensity of reflections from grain boundaries and non-uniformity of metal, which are not defects, grows.

When inspecting the details, the UT frequency is determined mainly by the attenuation coefficient, the level of structural reverberation of the material, and the dimensions of the product being monitored. Knowing these characteristics, it is possible to estimate and choose the optimal frequency, which will ensure the greatest sensitivity of the control with minimal energy loss to scattering and absorption by grains of metal.

In metals with pronounced anisotropy (copper, zinc), which occurred in the case under consideration and in some alloys with complex phase composition, ultrasound is strongly scattered. The attenuation coefficient for these metals is ten times higher than for alloys with a small degree of elastic anisotropy. As a rule, the sounding of such metals is accompanied by structural reverberation - gradual attenuation of ultrasonic testing due to multiple repeated reflec-tions of waves from the grain boundaries of metal. As a result of this, interference may appear on the flaw detector screen, which significantly complicates the UT inspection. If the level of structural reverberation is small, then details can be sounded at a sufficiently high frequency. Otherwise, the frequency must be significantly reduced. In the case described, the best results were obtained using piezoelectric transducers with an operating frequency of $0.6 \mathrm{MHz}$.

When testing the material of the monument, the situation was largely complicated by the presence of an unpredictable surface corrosion layer a hundred years old, the removal of which was impossible under the conditions of work. In addition to corrosion, the metal of the monument was also covered with a layer of patina, which was an artificially applied layer of a rather thick oxide 
film. All this greatly hampered the input and reception of ultrasonic waves, and the interpretation of the results.

Thickness measurement was carried out using a portable, easy-to-use UT-93P thickness gauge, which has the ability to tune out interference, displays the results in a digital form on a liquid-crystal digital display and has an indication of the reliability of contact with the product being monitored. The manufactur-er produces a device configured to control steel products, so for the work it was necessary to reconfigure it to control bronze. Eentering and receiving a UT in the material of the monument was significantly difficult.

Reliability of indications when carrying out thickness gauging is ensured only with reliable input and reception of ultrasonic testing. In our case, as already noted, the monument has practically no flat areas with good surface cleanliness, is fully cov-ered with patina, corrosion products and contamination. According to the con-ditions of work, the cleaning of the monument was not allowed, which could spoil its appearance, so it was necessary to carry out control in the above con-ditions, which did not always allow achieving stability of the readings (Gubenko et al., 1980). For measurements, P112-10-6/2-AVT-05 converter was chosen, designed for a rough, uneven surface, with a contact pad of $6 \mathrm{~mm}$ in diameter.

According to the slinging scheme proposed and agreed with the customer, it was necessary to determine the metal thickness at the points of application of the distributed load from soft slings to the horse's belly (to prevent punching) and to the thinned sections of the legs (to prevent tearing under the plinth and legs).

The most thinned places of the monument were identified and the ac-tual loads were calculated. Flaw detection was performed using UD2-12 and UD12-22 ultrasonic domestic flaw detectors. The control was carried out according to a specially developed methodology. Ultrasonic inspection of weld joints of the plinth and connections of the horse's legs gave disappointing results. As already noted, it was not possible to reliably determine the method of connection, but it was found that the connection was not equal in strength to the rest of the material.

Nearly all welds have lack of fusion throughout the cross section of the seams; there is a clear boundary between the base and the weld metal. The connection cannot be attributed to structural ones as it is purely decorative in nature and should be supported when lifting the monument, as indicated in the slinging scheme.

Ultrasonic diagnostics made it possible to determine the strength and de-formative properties of the metal in the above places. In our case, the problem was somewhat facilitated, since by the time the work was carried out, there had already been obtained the results of the chemical analysis of the material and the values of the strength and deformative properties of the material in this place (Potapov et al., 2016). Having measured the UT speed in the same place and then measuring it in other places of interest, the elasticity modulus variation was determined from the velocity variation.
Measurements were made using UKB-1M ultra-sonic velocity meter and UD2-12 flaw detector with a velocity measurement mode.

However, the ultrasonic inspection speeds in all five parts of the monument were measured. The average speed was 5120 meters per second. No dangerous anomalies, indicating a change in the struc-ture of the material of the monument, significant microcrystalline corrosion or fracturing were detected. The metal in all places was quite homogeneous.

The study of the chemical composition of the alloy and its structure, as well as the embedding material of defects.

The monument to Alexander III is cast from the socalled green art bronze. 8 tons of bronze were used for casting. The chemical composition was determined by the X-ray fluorescence method using Philips PW-1220C scanning spectrometer according to STP 90.208-83 method with the help of "Centrolab" association. The following val-ues of the mass fractions of the components were established: tin $8 \%$, zinc $8 \%$, lead $1 \%$, the rest is copper. The grade, according to modern classification, could be called OCS-8-8-1.

Of the existing standard art grades, it is close to $\mathrm{BH}-1$, which has a slightly lower content of alloying.

The strength of the metal of the monument is about $150-200 \mathrm{MPa}$, and the relative elongation $-8-12 \%$.

The alloy has good casting properties (zinc additives), increased density and good processability (lead additives).

A metallographic study, also conducted with the involvement of employees and equipment of "Centrolab" association, allowed to establish that the material of the monument has developed dendritic segregation and is a $\alpha$-solid copper solution + eutectoid $\left(\mathrm{Cu}_{31} \mathrm{Sn}_{8}+\alpha\right)$.

According to the results of the $\mathrm{X}$-ray fluorescence analysis, the material for embedding defects is zinc $(\mathrm{Zn}-$ $98.6 \%, \mathrm{~Pb}-1.2 \%)$.

\section{Conclusion}

To preserve the historical and cultural heritage, a regular survey of the technical condition of the monuments is necessary not only in preparation for extreme conditions, such as moving, transporting and changing the storage conditions of the monument, but also to assess its current state for timely restoration and conservation, as well as the preparation of technical documenta-tion such as passports of objects of history. At the same time, methods of non-destructive testing of quality of materials and structures are stipulated as spar-ing and not leading to the occurrence of irreversible phenomena of product destruction.

The technique, representing a set of methods for nondestructive testing, the study of the technical condition of objects of decorative and applied art, is aimed at identifying defects in materials and structure, their physical and mechanical characteristics, thickness in dangerous sections and the carrying ca-pacity of the connections of individual elements, namely:

- visual-optical method is applicable when determining external defects, as well as for determining 
the internal structure of the monument, connections of its individual parts and their technical state;

- capillary method is used to determine the presence of microcracks in strained places, their actual size and orientation;

- acoustic-ultrasonic method is applied when detecting internal defects, i.e. in case of flaw detection, as well as to determine metal thickness in the most strained places, i.e. for thickness gauging;

- acoustic-ultrasonic pulse method is used when determining physical and mechanical properties of metal, i.e. for diagnostics;

- thermal imaging method is applicable when determining the quality of the connections of individual parts of the product;
- X-ray fluorescent method - to determine the chemical composition of materials;

- metallographic method is used when analyzing the microstructure of materials.

Thus, timely analysis of the technical condition of materials and structures of cultural heritage monuments contributes not only to the accumulation of scientific and technical data for assessing the dynamics of the state of elements, but also to the development of scientific and restoration potential to preserve objects of historical, cultural, architectural value.

It also helps to accumulate factual material about the structure and materials of monuments for working out of recommendations for further research and restoration of similar items. 


\section{Architecture and Engineering Volume 4 Issue 1}

\section{References}

Aleshin, N.P. (1989). Methods of acoustic control of metals. Moscow: Mashinostroenie.

Baranov, V.V. (2013). On the question of the authenticity and safety of the royal gates of the "VN Laurina group". In: Proceedings of the international scientific and methodical conference "Research on the conservation of cultural heritage", pp. 51-61.

Chistyakov, A.N., Krogius, M.E. (2014). Typology of the destruction of cultural monuments. St. Petersburg: SPbKO.

Fomin, I.V., Zaychikova, S.Yu. (2008). Technical Means for Monitoring Temperature, Humidity and Light Regimes in Museums and Architectural Monuments. In: Proceedings of the international scientific and methodical conference "Research on the conservation of cultural heritage", pp. 196-205.

Gavrilenko, L.S., Grigorieva, I.A., Gribanov, A.V., Novikova, O.G. (2008). Application of a complex of microanalytical methods for studying the composition of materials and their degradation products under the influence of external adverse factors. In: Proceedings of the international scientific and methodical conference "Research on the conservation of cultural heritage", pp. 129-148.

Gubenko, L.A., Lukachev, S.V., Polyakov, V.E. (1980). Investigation of the moduli of branchwood. Forest Journal, 5, pp. 65-67. Nagaeva, Z.S., Zhivitsa, V.V., Sidorova, V.V. (2018). Reconstruction and Resto-ration of Cultural Heritage Objects. Moscow: Buk. Potapov, A.I. (1980). Quality control and prediction of the reliability of structures made of composite materials. Leningrad: Mechanical Engineering.

Potapov, A.I., Filipovsky, Y.V., Karabuta, V.S. (2016). The need for and the possibility of using ultrasound in assessing the current state of monuments from rocks. In: Proceedings of the IV International scientific and practical conference "Innovations in transport and mechanical engineering", pp. 123-126.

Rogachevsky, V.M. (1965). Monument to Alexander III. Leningrad: Nedra, pp. 202-208.

Pedashenko, S.A. (1912). Monuments to Alexander III. Moscow: Partnership of the A.I. Memontov Publishing House.

Rebrikova, N.L. (2008). Practical Guide on Diagnostics of Microbiological Damage of Art and Culture Monuments. Moscow: KMK Fellowship of Scientific Publications.

Schmidt, I.M. (1989). From the history of world art of Russian sculpture of the second half of the 19th-20th centuries. Moscow: Iskusstvo.

State Duma (2019). "On the objects of cultural heritage (historical and cultural mon-uments) of the peoples of the Russian Federation".Federal Law of June 25, 2002 No. 73-FZ (as amended on February 21, 2019). 